Journal of Advanced Computer Science \& Technology, $8(2)(2019) 23-31$
JPC
Weurnal of Advanced Computer Science \& Technology $w w$. Sciencepubco.com/index.php/JACST
Research paper

\title{
Taxonomy of bio-inspired optimization algorithms
}

\author{
Saman M. Almufti ${ }^{1}$ *, Ridwan Boya Marqas ${ }^{2}$, Vaman Ashqi Saeed ${ }^{1}$ \\ ${ }^{1}$ College of Computer Science \& Information Technology, Nawroz University, Duhok, Kurdistan-Region, Iraq \\ ${ }^{2}$ Department of Information Technology, Duhok Private Technical Institute, Duhok-kurdistan Region, Iraq \\ *Corresponding author E-mail: Saman.Almofty@gmail.com
}

\begin{abstract}
Bio-Inspired optimization algorithms are inspired from principles of natural biological evolution and distributed collective of a living organism such as (insects, animal, .... etc.) for obtaining the optimal possible solutions for hard and complex optimization problems. In computer science Bio-Inspired optimization algorithms have been broadly used because of their exhibits extremely diverse, robust, dynamic, complex and fascinating phenomenon as compared to other existing classical techniques.

This paper presents an overview study on the taxonomy of bio-inspired optimization algorithms according to the biological field that are inspired from and the areas where these algorithms have been successfully applied
\end{abstract}

Keywords: Bio-Inspired Algorithms (BIA); Ecology-Based Algorithms (ECO); Swarm Intelligence (SI); Elephant Herding Optimization (EHO); Evolutionary Algorithms (EA).

\section{Introduction}

The increasing and complexity of real-life problems motivates the researchers to search and develop useful methods for finding and optimizing the solutions of complex and optimization problems (Kumar, Chhabra \& Kumar, 2014).

In last few decades, Bio-inspired algorithms (BIA) have shown significant proficiency in solving many optimization problems. Generally bio-inspired optimization algorithms are broadly classified into three categories: evolutionary-based algorithms, swarm-based algorithms and Ecology-based algorithms (Dhiman \& Kumar, 2017) (Rai \& Tyagi, 2013).

Evolutionary-based algorithms (EA) are stochastic search methods that simulate the natural biological evolution and the social behavior of living species such as reproduction selection, recombination and mutation, Evolutionary-based algorithms have been developed to find the optimal or near-optimum solutions to large-scale optimization problems, for which traditional mathematical techniques may fail, one of the most known Evolutionary-based algorithms in the computer science field is the Genetic Algorithm (GA) (Holland, J. H. 1975).

Swarm intelligence (SI), is concerned with the designing and developing of intelligent interactive multi-agent systems which cooperate to gather to achieve a specific goal that cant be achieved by a single-agent (Almufti, 2017). Swarm intelligence is defined by Dorigo M as "The emergent collective intelligence of groups of simple agents"( Li, Y., 2010). Swarm-based algorithms are inspired from behaviors of some social living beings in the nature, such as ants, birds, bats, bees, termites, and fishes (Almufti, 2017). One of the most known Swarm intelligence algorithms in the computer science field is the Ant Colony Optimization (ACO) (Renas \& Abdulnabi 2018).

Ecological-inspired algorithm (ECO) is an assessment to develop cooperative search algorithms, it depends on populations of individuals and each population develops according to a search strategy. In a way, that the individuals of each population are modified according to the mechanisms of diversification, intensification and the initial parameters of the search strategy (Begon \& Harper, 2006). The ecological inspiration stems from the use of some ecological concepts, such as: habitats, ecological relationships and ecological successions (May \& McLean, 2007). One of the most known ecological inspired algorithms in the computer science field is the Biogeography-Based Optimization (BBO).

This paper presents an overview study of bio-inspired optimization algorithms such as (Ant Colony Optimization, Particle Swarm Optimization, Biogeography-Based Optimization, Artificial Bee Colony Algorithm, Elephant Herding Optimization, ... etc.) according to its deferent classification (evolutionary-based, swarm-based and Ecology-based) and the biological field that are inspired from and the areas where these algorithms have been successfully applied.

\section{Bio-inspired algorithms (BIAs) taxonomy}

Real-world optimization problems are often very difficult to solve and involve multi-objective optimization. Most of the Real-world optimization problems are NP-hard problems, which cannot be solved using the traditional deterministic algorithms (Rai \& Tyagi, 2013). BioInspired algorithms have been confirmed to be excellent methods to address these complex optimization problems, and have been applied to solve many such problems belonging to different domains. Over the past few decades, various Bio-Inspired Algorithms have been developed, taking inspiration from deferent biological swarms that occur in nature (Binitha, et al,2012).

Figure (1) presents a graphical classification of some of well-known Bio-Inspired Algorithms (Dubey, Panigrahi \& Pandit, 2014). 


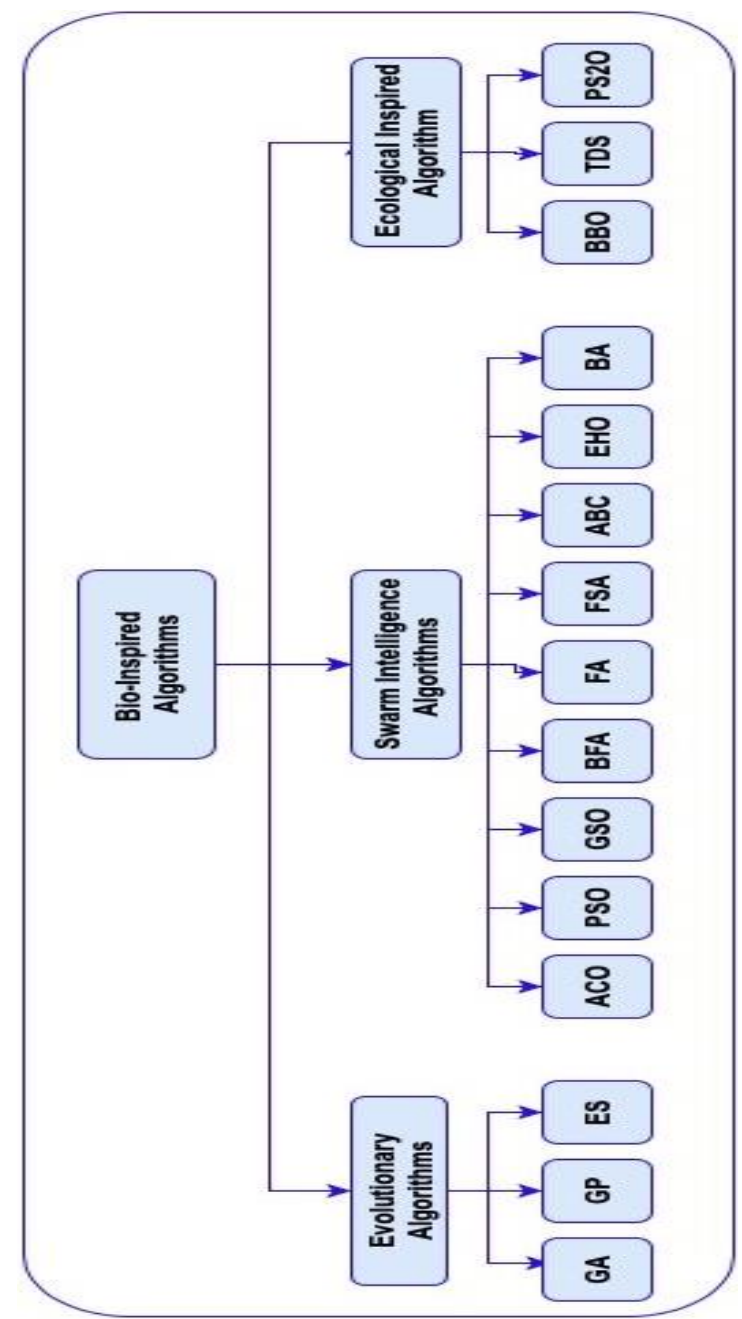

Fig. 1: Bio-Inspired Algorithm Taxonomy.

Table (1) shows the meaning of the Abbreviation's of the bio-inspired algorithms that are used in the figure (1).

Table 1: Meaning of the Abbreviations

\begin{tabular}{ll}
\hline Abbreviation & Full-Form of the Algorithm \\
\hline GA & Genetic Algorithm \\
GP & Genetic Programming \\
ES & Evolutionary Strategy \\
ACO & Ant Colony Optimization \\
PSO & Particle Swarm Optimization \\
GSO & Glowworm Swarm Optimization \\
BFA & Bacterial Foraging Algorithm \\
FA & Firefly Algorithm \\
FSA & Fish School Algorithm \\
ABC & Artificial Bee Colony \\
EHO & Elephant Herding Optimization \\
BBO & Biogeography Based Optimization \\
TDS & Temperature Dependent Sex \\
PS2O & Symbiosis \\
\hline
\end{tabular}

The performance of many global optimization techniques, such as genetic algorithms (GA) is dependent mainly on the evolutionary settings of these algorithms. For example, by choosing changing the values of mutation and crossover, GA may lead to different optimization results and convergence speed. Generally the requirements for an effective Optimization algorithms (Bio-Inspired, Natural Inspired, Conventional, Non-Conventional) involves (Storn \& Price, 1997):

a) Minimize time, cost, and effort for solving complex optimization problems.

b) Ability to handle non-differentiable, nonlinear and multimodal cost functions.

c) Parallelizability to cope with computation intensive cost functions.

d) Good convergence properties, i.e. consistent convergence to the global minimum in consecutive independent trials.

e) Ease of use, i.e. few control variables to steer the minimization. These variables should also be robust and easy to choose.

\section{Evolutionary algorithms (EA)}

Evolutionary algorithms (EAs) are the most well known, traditional and established algorithms between the nature inspired algorithms, inspired from the biological evolution in nature. In the passed year EA are extensively used for solving various specializations of science 
and real-time applications to find an optimum solution for complex and optimization problems (Das \& Suganthan, 2011). The word Evolutionary algorithm is used to define a collection of optimization techniques that simulate the natural biological evolution and the social behavior of living species. Differential Evolution (DE), Evolutionary strategy (ES), Genetic algorithm (GA), Genetic programming (GP), and Granular Agent Evolutionary Algorithm are the most well-known Algorithms belongs to Evolutionary algorithms (EAs) (Holland, J. H. 1975).

\subsection{Genetic algorithm (GA)}

In the field of artificial intelligence, the genetic algorithm (GA) is an evolutionary computation algorithms used to generate useful solutions to optimization and search problems. Genetic algorithms belong to the larger class of evolutionary algorithms (EA), which generate solutions to optimization problems using techniques inspired by natural evolution, such as inheritance, mutation, selection, and crossover (DeJong, K. 1975). GA is inspired by the principles of genetics and evolution, and mimics the reproduction behavior observed in biological populations; it belongs to stochastically search algorithm bases on principles of natural selection and recombination (Holland, J. H. 1975). GA develops a population of initial individuals called chromosomes, where each chromosome denotes a solution to the problem to be solved. Each chromosome composed of set of genes, by applying recombination to these structures; such as crossover and mutation they attempt to find an optimal solution for a given problem (Thengade \& Dondal, 2012).

Genetic algorithms successfully applied to solve problems related to deferent fields such as NP-Hard Problems, mathematics, computational science, phylogenetics, bioinformatics, engineering, economics, chemistry, manufacturing, physics, pharmacometrics and other fields (Goldberg, 1989). Figure (2), shows the procedure how Genetic Algorithm works.

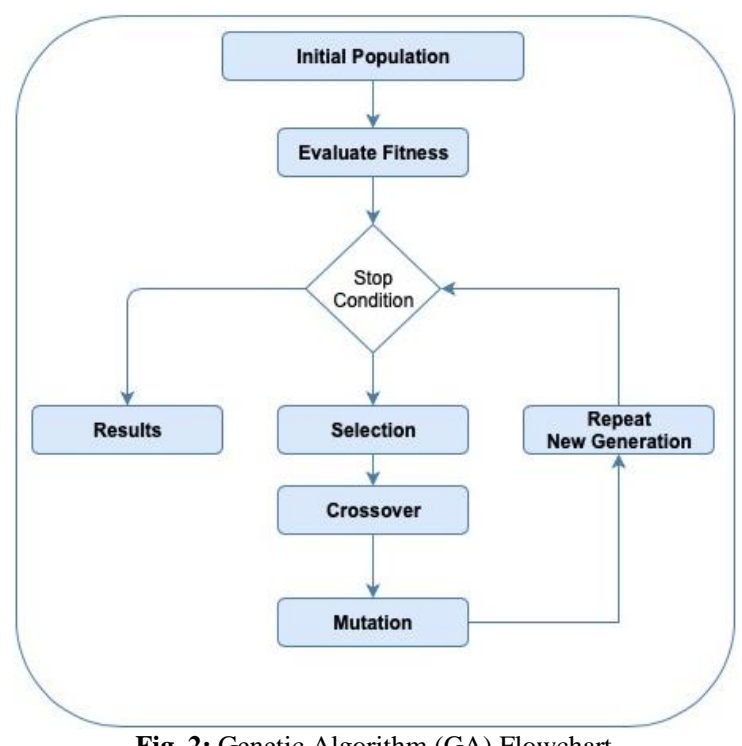

Fig. 2: Genetic Algorithm (GA) Flowchart.

\subsection{Evolutionary strategy ES}

In computer science, an Evolution Strategy (ES) is an optimization technique established on the ideas of evolution and adaptation (Sukale \& Biradar, 2015). It belongs to the general class of evolutionary computation organizations. ES evolve individuals by means of mutation and discrete or intermediate recombination (Li \& Heinemann, 2007). ES algorithms are designed particularly to solve problems in the realvalue domain. They use self-adaptation to adjust control parameters of the search. Figure (3), shows the procedure how Evolution Strategy Algorithm works.

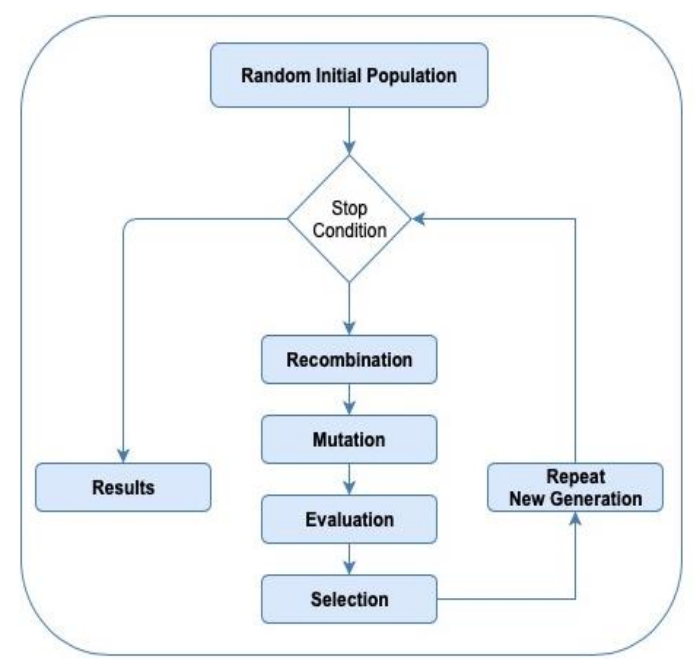

Fig. 3: Evolution Strategy (ES) Flowchart. 


\section{Swarm intelligence SI}

Swarm Intelligence (SI) is the field of studying and designing well-organized computational intelligent interactive multi-agent systems that cooperate to gather to achieve a specific goal and to solving complex optimizations problems by using the behavior of real living swarms such as birds, fish, and ants (Almufti, 2017). SI is a part of Artificial Intelligence (AI) introduced by Jing Wang and Gerardo Beni in 1989 in the global optimization framework as a collection of algorithms for controlling robotic swarms (Beni \& Wang, 1989).

\subsection{Ant colony optimization ACO}

The Ant Colony Optimization (ACO) Algorithm is a heuristic algorithm uses the behavior of real ant in finding the shortest way between its current location and a source of food (Almufti, 2017) (Almufti \& Shaban, 2018).. Naturally, ants are an intelligent insects that lives and cooperate together in swarms (colonies), ants of a swarm are indirectly communicates with each other by an odorous chemical substance that ants can deposit and smell called pheromone trails (Dorigo \& Maniezzo, 1996) (Almufti \& Shaban, 2018).. In a swarm, each ant which represent an agent of swarm randomly laying down a pheromone trail in its way to a food source, if any Ant finds a source of food, it return to the nest by smelling pheromone trail, in case of increase of pheromone in any path all the other agents follow that path (Renas \& Abdulnabi, 2018).

Figure (4), shows the procedure how Ant Colony Optimization (ACO) Algorithm works.

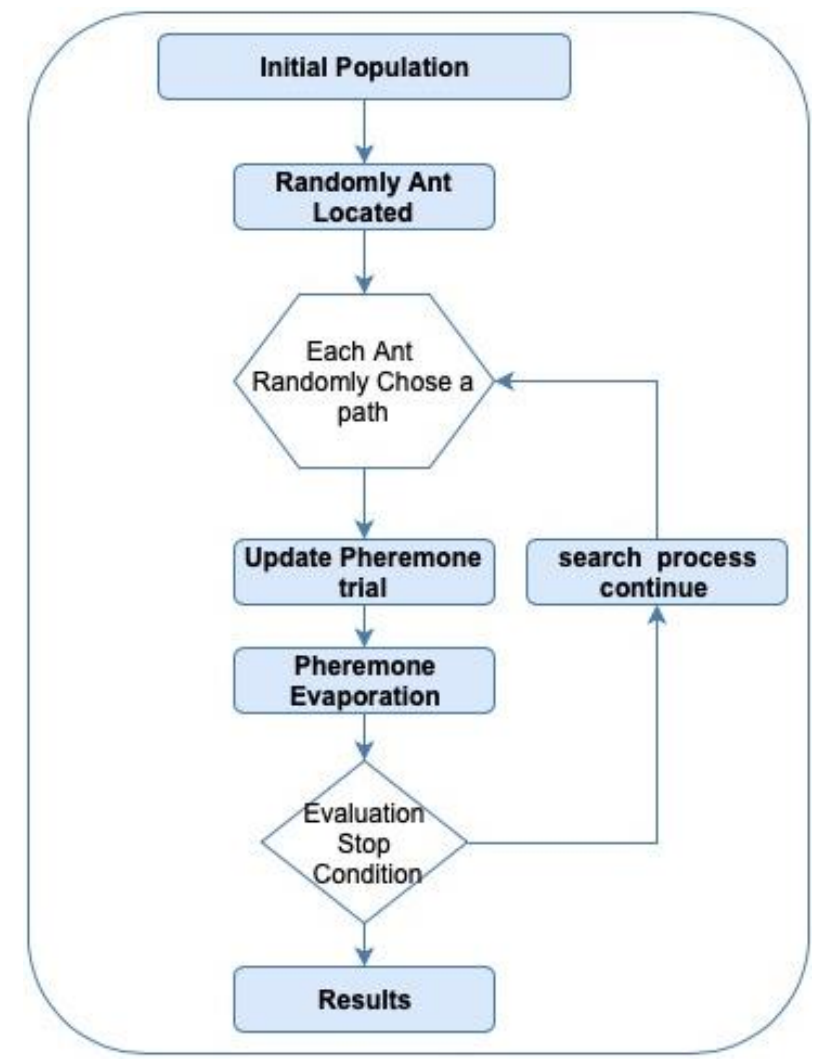

Fig. 4: Ant Colony Optimization (ACO) Flowchart.

\subsection{Particle swarm optimization PSO}

The Particle Swarm Optimization (PSO) algorithm concept comes from the social behavior of organisms such as fishing, schooling bird flocking, it is widely used to solve computational problems. PSO particles cooperate between themselves as one group to reach their goal (Almufti, 2017).

PSO simulates this social behavior as an optimization tool to solve some optimization problems and NP-Hard problems such as Travelling Salesman Problem (TSP) (Almufti, 2015) (Almufti \& Shaban, 2018). Figure (5) shows the procedure how Particle Swarm Optimization (PSO) Algorithm works. 


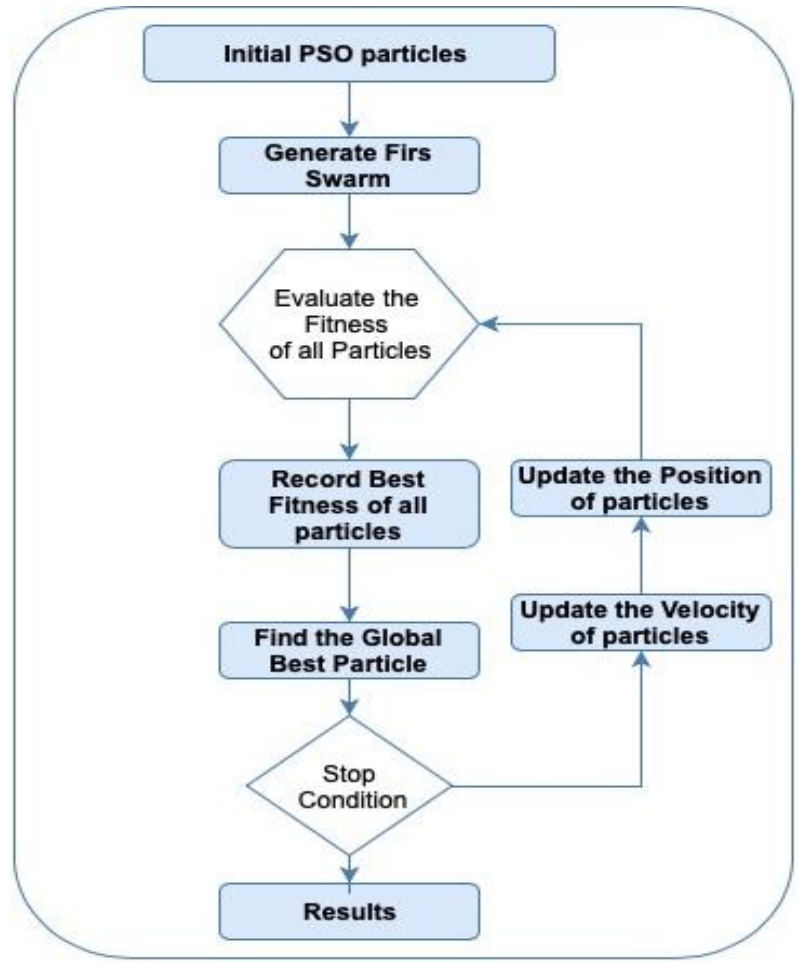

Fig. 5: Particle Swarm Optimization (PSO) Flowchart.

\subsection{Elephant herding optimization EHO}

Elephant herding optimization (EHO) algorithm is a swarm based metaheuristic search method (Wang, 2015) for solving optimization problems. The algorithm arises from modeling of herding behavior of real elephants in nature (Almufti, 2019).

The herding behavior is that in a population of elephants contains a number of subgroups, known as clans, which comprise a number of Female elephants and Calves. Each clan moves under the leadership of a matriarch. Male calves that reached adulthood leave the clan they belongs (Wang, 2015). Figure (6) shows the procedure how Elephant herding optimization (EHO) Algorithm works (Almufti, 2019).

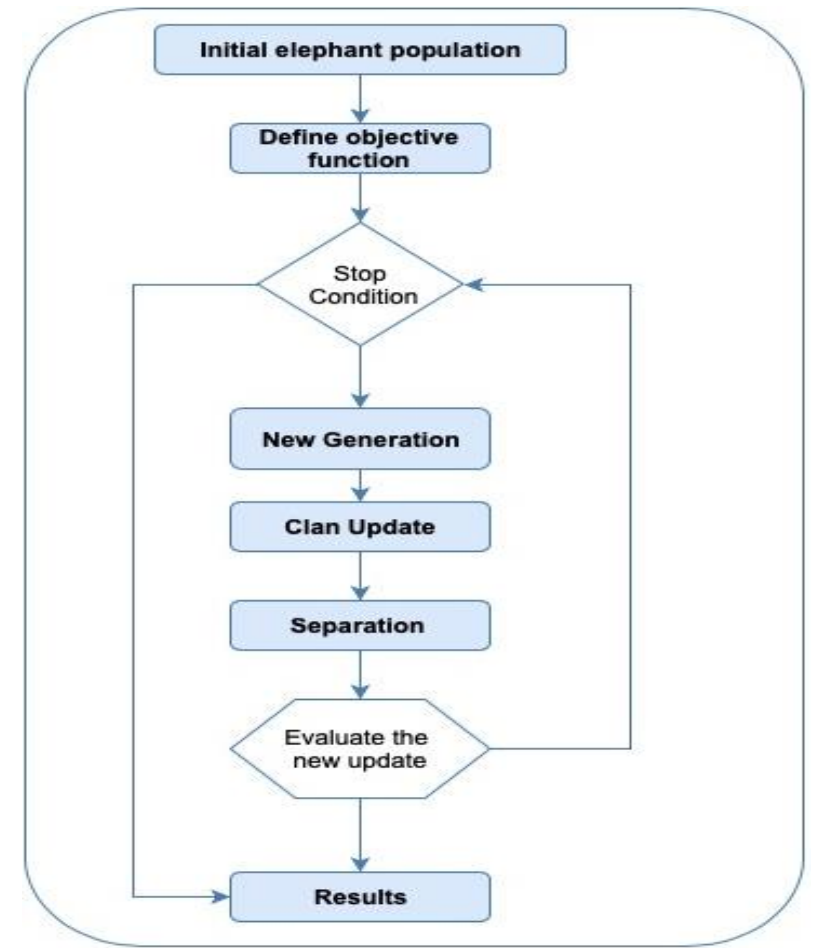

Fig. 6: Elephant Herding Optimization (EHO) Flowchart. 


\section{Ecological-inspired algorithm ECO}

Natural ecosystems provides rich source of techniques for designing and solving difficult computer science problems. It includes the living organisms along with the abiotic environment in which organisms interact such as soil, air, water etc. There can be numerous and complex types of interactions among the species of ecosystem.

Ecological-inspired algorithm (ECO) is an assessment to practice the interactions among the species of ecosystem to design and develop cooperative and intelligence algorithms, it depends on populations of individuals and each population develops according to a particular search strategy. In a way, that the individuals of each population are modified according to the mechanisms of diversification, intensification and the initial parameters of the search strategy (Begon \& Harper, 2006). The ecological inspiration stems from the use of some ecological concepts, such as: habitats, ecological relationships and ecological successions (May \& McLean, 2007).

\subsection{Biogeography based optimization BBO}

Biogeography is nature's way of distributing species over time and space; that is the immigration and emigration of species between habitats (Binitha, et al,2012), and is equivalent to general problem solutions.

Biogeography-Based Optimization (BBO) Algorithm is a global optimization algorithm developed and inspired from the mathematical models of biogeography (Simon, 2008). This population-based algorithm uses the idea of the migration strategy of animals or other species for solving optimization problems.

$\mathrm{BBO}$, just like other optimization algorithms (GA, ACO, PSO, ...etc.), is a population-based algorithm in which a population of candidate solutions is used for solving a global optimization problem. In BBO, the initial population is not ignored among different generations. Instead, the migration concept is used to modify the population (Rahmati \& Zandieh, 2011). As another distinction, in every generation, the fitness function is not used directly to modify the population; BBO used fitness to determine the immigration and emigration rates. Applications that use these ideas allow information sharing between candidate solutions (Simon, 2008).

In BBO, each habitat is considered as an individual and has its habitat suitability index (HSI) instead of fitness value to show the efficiency of individual (Alroomi, Albasri \& Talaq, 2013). High- HSI habitat denotes a good solution and low-HSI habitat denotes a poor solution. Solution features emigrate from high-HSI habitats which is called emigrating habitat to low-HSI habitats which is called immigrating habitat (Rahmati \& Zandieh, 2011). Figure (7) shows the procedure how Biogeography-Based Optimization (BBO) Algorithm works.

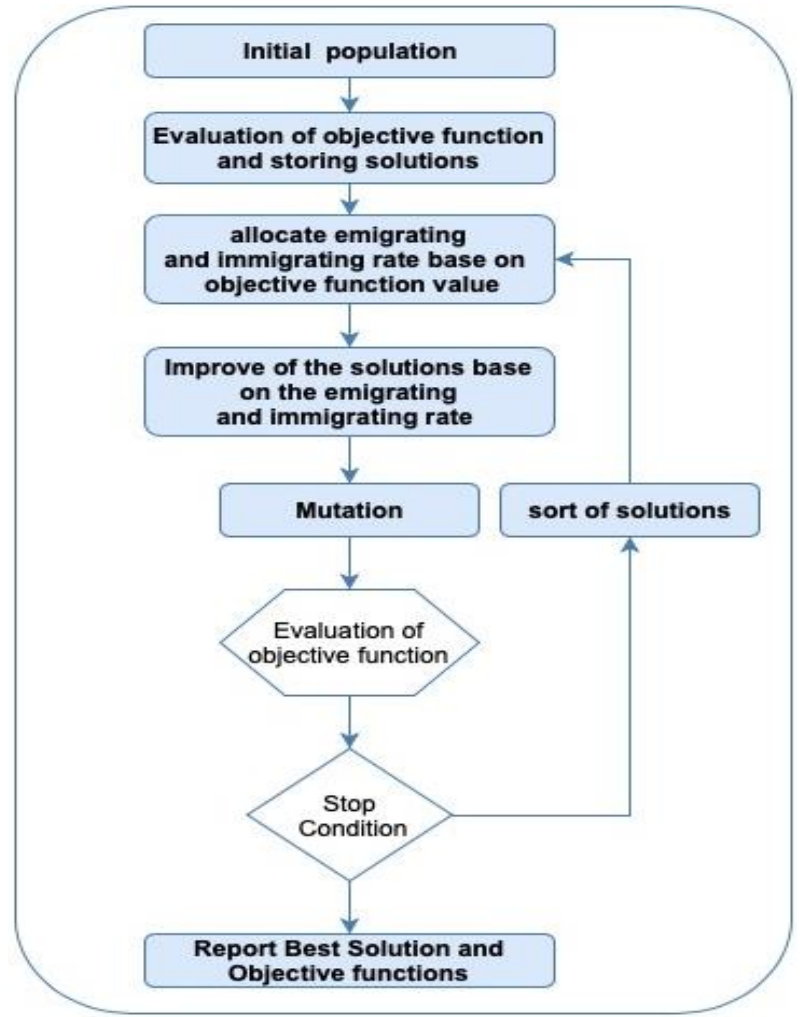

Fig. 7: Biogeography-Based Optimization (BBO) Flowchart.

\subsection{PS2O}

$\mathrm{PS}^{2} \mathrm{O}$ is a multi-species optimizer method extends the dynamics of the basic PSO algorithm by adding a significant ingredient that takes into account the symbiotic co evolution between species. Symbiosis is the living together of organisms from different species, and it's almost the ubiquitous technique in nature. $\mathrm{PS}^{2} \mathrm{O}$ inspired by the ideas from the co evolution of symbiotic species in natural ecosystems and heterogeneous interaction between species (Chen \& Zhu, 2008). Figure (8) shows the procedure how PS ${ }^{2} \mathrm{O}$ Algorithm works. 


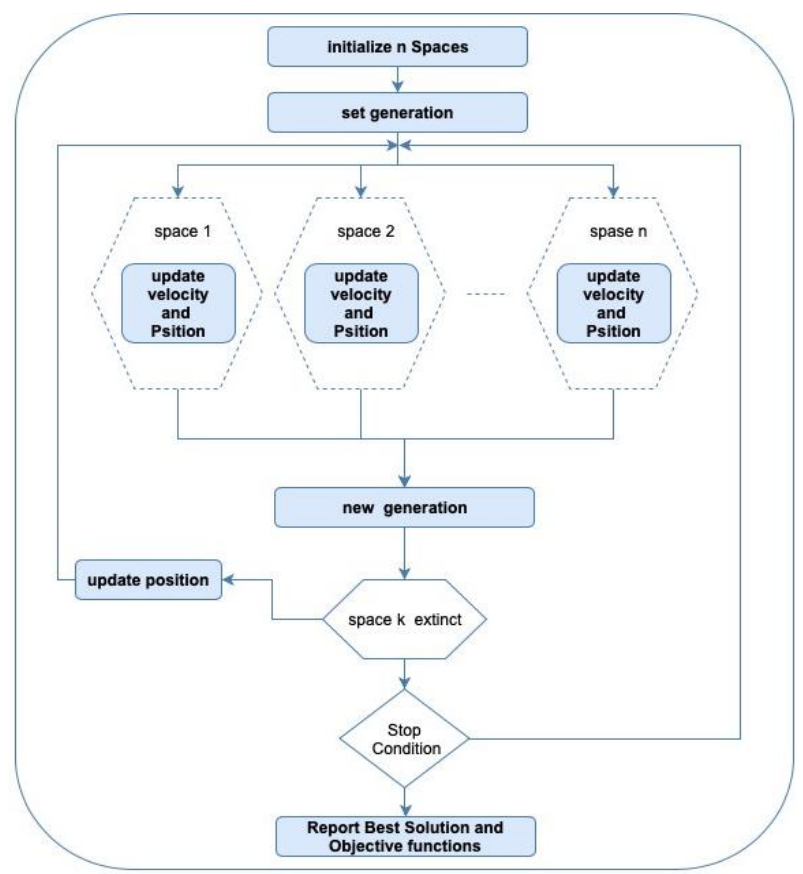

Fig. 8: $\mathrm{PS}^{2} \mathrm{O}$ Flowchart.

\section{Summery}

Table 2: Presents A Summary of the Taxonomy of Bio-Inspired Algorithms, Represented in Terms of the Abbreviations, Name, the Author or Scientist Name, Presented Year, Mechanism and Areas of Application

\begin{tabular}{|c|c|c|c|c|c|c|}
\hline Method & Name & $\begin{array}{l}\text { Author / } \\
\text { Scientist }\end{array}$ & Year & $\begin{array}{l}\text { Taxon- } \\
\text { omy }\end{array}$ & Mechanism & Area of Application \\
\hline GA & $\begin{array}{l}\text { Genetic Algo- } \\
\text { rithm }\end{array}$ & $\begin{array}{l}\text { John Hol- } \\
\text { land }\end{array}$ & 1960 & EA & $\begin{array}{l}\text { Selection, } \\
\text { Crossover, } \\
\text { Mutation, } \\
\text { Gene Silencing }\end{array}$ & $\begin{array}{l}\text { Computer aided design path planning of mobile robots, } \\
\text { Optimization problems in data mining and rule extraction, } \\
\text { various scheduling problems sensor-based robot path plan- } \\
\text { ning, dynamic and multiple criteria web-site optimizations } \\
\text {, decision thresholds for distributed detection in wireless } \\
\text { sensor networks, Web page classification system ,mini- } \\
\text { mum energy broadcast problem in wireless ad hoc net- } \\
\text { work, fixed charge transportation problem, assignment } \\
\text { problems, pattern recognition , reactive power dispatch, } \\
\text { multi-objective vehicle routing problem, flight control sys- } \\
\text { tem design, Power System Optimization problems, portfo- } \\
\text { lio Optimization ,optimal learning path in e learning, .... } \\
\text { Etc. }\end{array}$ \\
\hline $\mathrm{ES}$ & $\begin{array}{l}\text { Evolutionary } \\
\text { Strategy }\end{array}$ & $\begin{array}{l}\text { Bienert } \\
\text { Rechenberg } \\
\text { Schwefel }\end{array}$ & 1960 & EA & $\begin{array}{l}\text { Mutation, Recombi- } \\
\text { nation, Selection }\end{array}$ & $\begin{array}{l}\text { Image processing, clustering, Parameter estimation, com- } \\
\text { puter vision system, Task scheduling and car automation, } \\
\text { structural optimization, A multi-parametric evolution strat- } \\
\text { egies algorithm for vehicle routing problems, Evolution } \\
\text { strategy for gas-turbine fault-diagnoses, .... etc. }\end{array}$ \\
\hline $\mathrm{ACO}$ & $\begin{array}{l}\text { Ant Colony } \\
\text { Optimization }\end{array}$ & $\begin{array}{l}\text { Marco Dor- } \\
\text { igo }\end{array}$ & 1992 & SI & $\begin{array}{l}\text { Inspired from the } \\
\text { behavior of Ant }\end{array}$ & $\begin{array}{l}\text { TSP Problem, dynamic problem of data network routing, } \\
\text { continuous optimization and parallel processing implemen- } \\
\text { tations, vehicle routing problem, graph colouring and set } \\
\text { covering, agent-based dynamic scheduling, digital image } \\
\text { processing, classification problem in data mining, protein } \\
\text { folding problem, Quadratic Assignment problem (QAP) }\end{array}$ \\
\hline PSO & $\begin{array}{l}\text { Particle } \\
\text { Swarm Opti- } \\
\text { mization }\end{array}$ & $\begin{array}{l}\text { Kennedy } \\
\text { Eberhart }\end{array}$ & 1995 & SI & $\begin{array}{l}\text { Inspired from the so- } \\
\text { cial behavior of or- } \\
\text { ganisms }\end{array}$ & $\begin{array}{l}\text { Job-Shop Scheduling problem, } \\
\text { feature selection, multimodal biomedical image registra- } \\
\text { tion, Edge detection in noisy images, color image segmen- } \\
\text { tation, classification of instances in multiclass databases, } \\
\text { web service composition course composition, constrained } \\
\text { and combinatorial optimization } \\
\text { Power System Optimization problems (economic dispatch- } \\
\text { ing), various scheduling problems, vehicle routing prob- } \\
\text { lems, prediction of tool life in ANN, multi-objective, dy- } \\
\text { namic, problems ,QoS in adhoc multicast, Anomaly finding } \\
\text { optimal machining parameter assembly line balancing } \\
\text { problem in production and operations management,detec- } \\
\text { tion, constrained portfolio optimization problem, selective } \\
\text { particle regeneration for data clustering, sequential order- } \\
\text { ing problem, machinery fault detection, Unit commitment } \\
\text { computation, Signature verification Extracting rules from } \\
\text { fuzzy neural network, ...etc. }\end{array}$ \\
\hline
\end{tabular}




\begin{tabular}{|c|c|c|c|c|c|c|}
\hline $\mathrm{EHO}$ & $\begin{array}{l}\text { Elephant herd- } \\
\text { ing optimiza- } \\
\text { tion }\end{array}$ & Wang & 2015 & SI & $\begin{array}{l}\text { Inspired from the } \\
\text { herding behavior of } \\
\text { elephant in the clan }\end{array}$ & $\begin{array}{l}\text { Benchmark problems, Service Selection in QoS-Aware } \\
\text { Web Service Composition, Energy-Based Localization, } \\
\text { PID controller tuning, Appliance Scheduling in Smart Grid } \\
\text { identification, ...etc. }\end{array}$ \\
\hline $\mathrm{BBO}$ & $\begin{array}{l}\text { Biogeography } \\
\text { Based Optimi- } \\
\text { zation }\end{array}$ & Dan Simon & 2008 & $\mathrm{ECO}$ & $\begin{array}{l}\text { Inspired from math- } \\
\text { ematical models of } \\
\text { biogeography. } \\
\text { Mutation operator, } \\
\text { Migration operators } \\
\text { (immigration and } \\
\text { emigration) }\end{array}$ & $\begin{array}{l}\text { web-based BBO graphical user interface, constrained opti- } \\
\text { mization, the sensor selection problem for aircraft engine } \\
\text { health estimation, groundwater detection and satellite im- } \\
\text { age classification, power system optimization, optimal me- } \\
\text { ter placement for security constrained state estimation gen- } \\
\text { eral benchmark functions, global numerical optimization, } \\
\text {...etc. }\end{array}$ \\
\hline PS2O & PS2O & $\begin{array}{l}\text { Hanning } \\
\text { Chen, } \\
\text { Yunlong } \\
\text { Zhu }\end{array}$ & 2008 & $\mathrm{ECO}$ & $\begin{array}{l}\text { Inspired by the ideas } \\
\text { from the co evolu- } \\
\text { tion of symbiotic } \\
\text { species in natural } \\
\text { ecosystems. } \\
\text { Initializer, updater, } \\
\text { extinction, evaluator }\end{array}$ & $\begin{array}{l}\text { Cooperative Cognitive Wireless Communication, con- } \\
\text { structing collaborative service systems (CSSs) }\end{array}$ \\
\hline
\end{tabular}

\section{Conclusion}

Several Algorithms have been proposed to solve and optimize the difficult combinatorial optimization problems. Algorithms that are inspired from the natural and Biological behavior yield special attention for its performance.

This paper classified the bio-inspired Algorithms to three main categories: Swarm based algorithms, Evolutionary based Algorithms and Ecological based Algorithms.

Its concluded from the table Algorithms that listed some of applications of bio-inspired algorithms that: bio-inspired algorithms are successfully applied to solve problem in various fields.

\section{References}

[1] Almufti, S. (2017). Using Swarm Intelligence for solving NPHard Problems. Academic Journal of Nawroz University, 6(3), 46-50. https://doi.org/10.25007/ajnu.v6n3a78.

[2] Alroomi, A., Albasri, F., \& Talaq, J. (2013). Essential Modifications on Biogeography-Based Optimization Algorithm. Computer Science \& Information Technology (CS \& IT). Begon, M., Townsend, C. R. \& Harper, J. L., 2006 Ecology: from individuals to ecosystems, 4th ed. Oxford, UK: Blackwell Publishing.

[3] Beni, G., \& Wang, J. (1989). Swarm intelligence in cellular robotic systems. In NATO Advanced Workshop on Robots and Biological Systems, Il Ciocco, Tuscany, Italy.

[4] Binitha, S., SATHYA, S.S., (2012), A Survey of Bio inspired Optimization Algorithms. International Journal of Soft Computing and Engineering, Vol. 2, No. 2, pp 137-151.

[5] Chen, H., \& Zhu, Y. (2008). Optimization based on symbiotic multi-species coevolution. Applied Mathematics and Computation, 205(1), 47-60. https://doi.org/10.1016/j.amc.2008.05.148.

[6] Das S., Suganthan P., (2011), Differential evolution: a survey of the state-of-the-art, IEEE Trans.Evol. Comput.60(4) 1469-1479. https://doi.org/10.1016/j.amc.2008.05.148.

[7] DeJong, K. 1975. An Analysis of the Behavior of a Class of Genetic Adaptive Systems, PhD Dissertation, Department of Computer and Communication Sciences, University of Michigan, Ann Arbor. https://doi.org/10.1109/TEVC.2010.2059031.

[8] Dhiman, G., \& Kumar, V. (2017). Spotted hyena optimizer: A novel bio-inspired based metaheuristic technique for engineering applications. Advances in Engineering Software, 114, 48-70. https://doi.org/10.1016/j.advengsoft.2017.05.014.

[9] Dorigo M., Maniezzo V., A. (1996), Colorni, Ant system: optimization by a colony ofcooperating agents, IEEE Trans. Syst. Man Cybern. B $2629-$ 41. https://doi.org/10.1109/3477.484436.

[10] Dubey, H., Panigrahi, B., \& Pandit, M. (2014). Bio-inspired optimisation for economic load dispatch: a review. International Journal Of Bio-Inspired Computation, 6(1), 7. https://doi.org/10.1504/IJBIC.2014.059967.

[11] Goldberg, D.E., (1989), Genetic Algorithms in Search, Optimization, and Machine Learning, Addison - Wesley.

[12] Holland, J. H. 1975. Adaptation in Natural and Artificial Systems, University of Michigan Press. Ann Arber.

[13] Kumar, V., Chhabra, J., \& Kumar, D. (2014). Parameter adaptive harmony search algorithm for unimodal and multimodal optimization problems. Journal of Computational Science, 5(2), 144-155. https://doi.org/10.1016/j.jocs.2013.12.001.

[14] Li, C., \& Heinemann, P. (2007). A comparative study of three evolutionary algorithms for surface acoustic wave sensor wavelength selection. Sensors and Actuators B: Chemical, 125(1), 311-320. https://doi.org/10.1016/j.snb.2007.02.026.

[15] Li, Y., (2010), Solving TSP by an ACO-and-BOA-based Hybrid Algorithm. In: 2010 International Conference on Computer Application and System Modeling, pp. 189-192. IEEE Press,New York.

[16] May, R. M. C. \& McLean, A. R., 2007 Theoretical Ecology: Principles and Applications. Oxford, UK: Oxford University Press.

[17] Rahmati, S., \& Zandieh, M. (2011). A new biogeography-based optimization (BBO) algorithm for the flexible job shop scheduling problem. The International Journal of Advanced Manufacturing Technology, 58(9-12), 1115-1129. https://doi.org/10.1007/s00170-011-3437-9.

[18] Rai, D., \& Tyagi, K. (2013). Bio-inspired optimization techniques. ACM SIGSOFT Software Engineering Notes, 38(4), 1. https://doi.org/10.1145/2492248.2492271.

[19] Renas R. Assad, Abdulnabi, N. (2018). Using Local Searches Algorithms with Ant Colony Optimization for the Solution of TSP Problems. Academic Journal of Nawroz University, 7(3), 1-6. https://doi.org/10.25007/ajnu.v7n3a193.

[20] Simon, D., 2008. Biogeography-based optimization. IEEE Transactions on Evolutionary Computation. 12 (6), 702-713. https://doi.org/10.1109/TEVC.2008.919004.

[21] Storn, R., \& Price, K. (1997). Differential Evolution - A Simple and Efficient Heuristic for Global Optimization over Continuous Spaces. Journal of Global Optimization, 11(4), 341-359. https://doi.org/10.1023/A:1008202821328.

[22] Sukale, S., \& D. Biradar, T. (2015). Review of Nature Inspired Algorithms. International Journal of Computer Applications, 109(3), 6-8. https://doi.org/10.5120/19166-0625.

[23] Thengade, A. and Dondal, R. (2012). Genetic Algorithm - Survey Paper. International Journal of Computer Applications (IJCA), (0975 - 8887), pp.25-29.

[24] Wang, G., Deb, S. and Coelho, L. (2015). Elephant Herding Optimization. 2015 3rd International Symposium on Computational and Business Intelligence (ISCBI). https://doi.org/10.1109/ISCBI.2015.8. 
[25] Almufti S., \& Shaban A., (2018), U-Turning Ant Colony Algorithm for Solving Symmetric Traveling Salesman Problem, Academic Journal of Nawroz University, vol. 7, no. 4, pp. 45-49, Available: 10.25007/ajnu. v6n4a270. https://doi.org/10.25007/ajnu.v6n4a270.

[26] Almufti, S., R. Asaad, R., \& B. Salim, (2019). Review on Elephant Herding Optimization Algorithm Performance in Solving Optimization Problems. International Journal of Engineering \& Technology, 7(4), 6109-6114. 